\title{
3 Research Square

\section{Increased Serum Levels of Cadmium are Associated with an Elevated Risk of Cardiovascular Disease in Adults}

\section{Siyu Ma}

Children's Hospital of Nanjing Medical University

Jie Zhang

Children's Hospital of Nanjing Medical University

Cheng Xu

Nanjing Medical University

Min Da

Children's Hospital of Nanjing Medical University

Yang Xu

Children's Hospital of Nanjing Medical University

\section{Yong Chen}

Children's Hospital of Nanjing Medical University

Xuming Mo ( $\nabla$ mohsuming15@njmu.edu.cn )

Children's Hospital of Nanjing Medical University https://orcid.org/0000-0002-2264-6123

\section{Research Article}

Keywords: Cadmium, Cardiovascular disease, Blood lipids, Inflammation, Adults

Posted Date: May 28th, 2021

DOl: https://doi.org/10.21203/rs.3.rs-537965/v1

License: (c) (i) This work is licensed under a Creative Commons Attribution 4.0 International License.

Read Full License

Version of Record: A version of this preprint was published at Environmental Science and Pollution Research on August 6th, 2021. See the published version at https://doi.org/10.1007/s11356-021-157322. 


\section{Abstract}

Previous studies have determined the effects of exposure to some heavy metals on cardiovascular disease (CVD); however, the association between exposure to cadmium and CVD in adults remains unclear. The relationship between serum levels of cadmium and the risk of CVD was studied by analysing available data from 38,223 participants who participated in the National Health and Nutrition Examination Survey (NHANES) from 1999 to 2016. After adjusting for all covariates, we found that higher serum cadmium concentrations were positively related to both the overall risk of CVD (odds ratio (OR): $1.45 ; 95 \%$ confidence interval $(\mathrm{Cl}): 1.22,1.72 ; \mathrm{p}$ for trend $<0.001)$ and the risks of its subtypes, including congestive heart failure, coronary heart disease, heart attack and stroke. Elevated levels of cadmium were associated with increased levels of lipids and inflammation parameters, including blood triglycerides, total cholesterol, white blood cells (WBCs) and C-reactive protein (CRP). Our study provided epidemiological evidence that cadmium may increase the risk of CVD by elevating blood lipids and inflammation.

\section{Capsule}

High blood levels of Cd are associated with increased risks of overall CVD and four of the CVD subtypes

\section{Introduction}

Cardiovascular diseases (CVDs), which include heart and vasculature diseases such as coronary heart disease (CHD), angina, heart attack (HA), heart failure (HF) and stroke, is a leading cause of death worldwide.(Xu et al. 2020a) According to a report from the American Heart Association (AHA) in 2010, CVD mortality accounted for nearly $33 \%$ of all mortality; and one person died from CVD every 38 seconds. Moreover, more than 785,000 people were estimated to have new or recurrent CVD every year.(LloydJones et al. 2010) Therefore, determining and controlling the risk factors for CVD are critical.(Phillips \&Guazzi 2015, Thiara 2015) Some new risk factors were recently identified in addition to traditional factors, such as smoking, high cholesterol, physical inactivity, obesity and diabetes.(Aw et al. 2020, Koller \&Agyemang 2020, Lloyd-Jones et al. 2010, Zhang et al. 2020). In particular, environmental pollution was found to contribute to the development of CVD and its risk factors.(Bi et al. 2020, Li et al. 2020c, So et al. 2020, Xu et al. 2020a) Of these, heavy metal pollutants (methylmercury, lead, chromium, etc.), which constitute one type of environmental pollutant, are associated with CVD and its risk factors.(Ali et al. 2020, Cao et al. 2020, Orisakwe et al. 2020) However, few studies have addressed the correlation between cadmium and CVD.

Cadmium (Cd) is a toxic heavy metal that is found in soil, water, seafood and vegetables.(Dennis et al. 2020, Gemeda et al. 2020, Koker et al. 2020, Orisakwe et al. 2015, Zhao et al. 2016) Many regions have reported levels of Cd exceeding the maximum permissible limit of $0.3 \mathrm{mg} . \mathrm{kg}^{-1}$ established by the World Health Organization (WHO). (Li et al. 2020a, Orisakwe et al. 2015, Orisakwe et al. 2020, Pan et al. 2016, Wang et al. 2018) In addition to natural sources, various human activities can increase levels of Cd, 
including smoking, traffic emissions, metallurgical processes, nuclear energy production, mining, coal combustion and chemical manufacturing.(Li et al. 2019, Li et al. 2018, Sall et al. 2020, Wu et al. 2019) Furthermore, similar to other heavy metals, the stability and permeation of Cd lead to its persistence and accumulation in vivo.(Wang et al. 2015, Wu et al. 2019) Therefore, the relationships between $\mathrm{Cd}$ and many diseases have attracted considerable attention. Cd was found to increase not only the risk of carcinogenesis but also noncancer-related mortality;(Al Amin et al. 2020, Amadou et al. 2020, Suwazono et al. 2020) exposure to Cd was shown to be associated with kidney function decline, the development of neurodevelopmental disorders and inflammation of the airways.(ljomone et al. 2020, Klein et al. 2020, Sotomayor et al. 2020) In addition, Cd was associated with elevated lipid levels and atherogenic indices, which might induce CVD in susceptible people.(Igharo et al. 2020, Xu et al. 2020b)

However, few studies have identified the relationship between Cd and CVD. A study in a Korean population showed that $\mathrm{Cd}$ was associated with the risk of stroke in people under the age of 60 years. An investigation in a larger and more representative population was needed to determine the correlation between the levels of Cd and CVD.(Jeong et al. 2020) Therefore, 38,223 subjects were included in this large population-based study based on data from the National Health and Nutrition Examination Survey (NHANES). Interestingly, the results showed that serum levels of $\mathrm{Cd}$ were positively related to CVD and its risk factors in adults.

\section{Material And Methods \\ 2.1 Subjects}

We included subjects who had participated in the NHANES, which is a program of studies involving members of the general, non-institutionalized population in the United States. The detailed survey design, methods, and available data are accessible on the NHANES website.

(https://www.cdc.gov/nchs/nhanes/) The subjects who participated in the NHANES, had available serum heavy metal concentrations and had CVD from 1999 to 2016 were enrolled in our study. In total, 92,062 adults completed the interviews and examinations, and those who were pregnant or had missing data were excluded. Figure 1 shows the participant selection process. Finally, our study enrolled 38,223 participants.

\subsection{Evaluation of outcomes}

The participants were evaluated by both a standardized medical questionnaire and self-reported physician diagnoses. The participants reported whether doctors or other health professionals had ever diagnosed them with CHD, congestive HF, angina, stroke or HA. A participant was considered to have CVD if a positive response was given to any of the relevant questions. The blood concentrations of lipids were measured by Roche Modular P and Roche Cobas 6000 chemistry analysers and the Friedewald equation. The Beckman Coulter method was used to measure the parameters of inflammation. 


\subsection{Exposure to cadmium}

Whole-blood samples were collected by a trained investigator and frozen before analysis. First, the blood samples were diluted. Then the serum cadmium levels were measured with an inductively coupled plasma mass spectrometer with dynamic reaction cell technology (ELAN® DRC II; PerkinElmer Norwalk, CT, USA). The quality assurance and quality control protocols followed the 1988 Clinical Laboratory Improvement Act mandates (https://www.cdc.gov/nchs/nhanes/index.htm).

\subsection{Covariate}

The covariates included age, sex, race, physical activity level, education level, poverty to income ratio (PIR), past-year alcohol consumption status, category of serum cotinine level, body mass index (BMI), family history of CVD and fish consumption; these covariates were selected based on factors that could affect the correlation between Cd levels and CVD risk. We treated age and PIR as continuous variables. Other variables were treated as categorical variables.

\subsection{Statistical analysis}

Continuous variables are presented as the means with standard deviations (SDs), and categorical variables are presented as frequencies and percentages. We compared continuous variables and categorical variables between groups with and without CVD with the Mann-Whitney $U$ test and $\chi^{2}$ tests, respectively, and analysed the correlations between the serum levels of heavy metals and the risk of CVD by survey-weighted multiple logistic regression analysis with three separate models. Model 1 was a crude model; Model 2 was adjusted for age, sex, race and education level; and Model 3 was adjusted for the variables included in Model 2 and BMI, PIR, physical activity, past-year alcohol consumption, serum cotinine, history of CVD, and fish consumption. We further investigated the relationships between serum concentrations of heavy metals and five CVD subtypes. Finally, multivariate analysis was used to explore the associations between serum Cd levels and blood lipids and inflammation parameters. Sampling weights were adjusted in all statistical analyses in SAS (version 9.2) and R software (version 3.5.0). We considered $\mathrm{P}<0.05$ to indicate statistical significance in this study.

\section{Results}

The demographics of the participants are shown in Table 1. Significant differences were found between subjects with and without CVD for age, sex, race, education level, PIR, physical activity level, past-year alcohol consumption, family history of CVD, serum cotinine category, BMI category and fish consumption. 
Table 1

Participants characteristics ( $N=38,223)$ in NHANES 1999-2016.

\begin{tabular}{|c|c|c|c|}
\hline & Non-CVD & CVD & $P$ value \\
\hline Age (years) & $45.30 \pm 0.20$ & $64.60 \pm 0.30$ & $<0.001$ \\
\hline Gender (\%) & & & $<0.001$ \\
\hline Male & 48.40 & 53.20 & \\
\hline Race (\%) & & & $<0.001$ \\
\hline Mexican American & 8.12 & 4.08 & \\
\hline Other Hispanic & 5.63 & 3.22 & \\
\hline Non-Hispanic White & 69.39 & 76.74 & \\
\hline Non-Hispanic Black & 10.65 & 10.96 & \\
\hline Other Race - Including Multi-Racial & 6.21 & 4.99 & \\
\hline Education Level (\%) & & & $<0.001$ \\
\hline Less Than 9th Grade & 5.97 & 12.16 & \\
\hline 9-11th Grade & 11.56 & 16.86 & \\
\hline High School Grad/GED or Equivalent & 23.73 & 26.98 & \\
\hline Some College or AA degree & 30.79 & 26.37 & \\
\hline College Graduate or above & 27.85 & 17.49 & \\
\hline Missing & 1.05 & 1.34 & \\
\hline Family PIR (\%) & & & 0.001 \\
\hline$<1$ & 12.80 & 15.94 & \\
\hline$>=1$ & 80.49 & 77.01 & \\
\hline Missing & 6.71 & 7.05 & \\
\hline Physical activity (\%) & & & $<0.001$ \\
\hline Never & 44.77 & 54.23 & \\
\hline Moderate & 26.01 & 26.29 & \\
\hline Vigorous & 28.47 & 14.34 & \\
\hline
\end{tabular}

Mean \pm SD. Percentage.

NHANES, National Health and Nutrition Examination Survey; BMI, body mass index; CVD, cardiovascular disease; PIR, poverty to income ratio; LOD, limit of detection. 


\begin{tabular}{|c|c|c|c|}
\hline & Non-CVD & CVD & $P$ value \\
\hline Missing & 0.76 & 5.15 & \\
\hline Past-year alcohol drinking (\%) & & & $<0.001$ \\
\hline No & 22.25 & 30.08 & \\
\hline Yes & 70.43 & 63.45 & \\
\hline Missing & 7.32 & 6.47 & \\
\hline Family history of CVD (\%) & & & $<0.001$ \\
\hline No & 77.52 & 66.34 & \\
\hline Yes & 20.36 & 30.24 & \\
\hline Missing & 2.12 & 3.42 & \\
\hline Serum cotinine category (\%) & & & $<0.001$ \\
\hline$<\mathrm{LOD}$ & 20.66 & 20.49 & \\
\hline LOD-10 & 51.46 & 51.48 & \\
\hline$>10$ & 26.60 & 25.98 & \\
\hline Missing & 1.28 & 2.05 & \\
\hline BMI category (\%) & & & $<0.001$ \\
\hline$<25$ & 32.70 & 21.68 & \\
\hline $25-30$ & 33.53 & 32.59 & \\
\hline$>=30$ & 32.57 & 41.93 & \\
\hline Missing & 1.19 & 3.81 & \\
\hline Fish consumption & & & $<0.001$ \\
\hline No & 14.05 & 13.08 & \\
\hline Yes & 66.00 & 60.22 & \\
\hline Missing & 19.96 & 26.70 & \\
\hline \multicolumn{4}{|l|}{ Mean \pm SD. Percentage. } \\
\hline $\begin{array}{l}\text { NHANES, National Health and } \\
\text { cardiovascular disease; PIR, pc }\end{array}$ & $\begin{array}{l}\text { on Survey; } \\
\text { o; LOD, limi }\end{array}$ & $\begin{array}{l}\text { mass } \mathrm{i} \\
\text { tion. }\end{array}$ & \\
\hline
\end{tabular}

Table 2 shows the correlations between the quartiles of the serum concentrations of three heavy metals and the risk of overall CVD according to the multivariate logistic regression model after adjustment for covariates. After adjusting for all covariates (model 3), we found that the risk of overall CVD was 1.45 
times (95\% Cl: 1.22, 1.72; $\mathrm{p}$ for trend < 0.001$)$ higher in the group with the highest quartile of serum Cd concentrations than in the group with the lowest quartile of serum $\mathrm{Cd}$ concentrations. No significant association was found between the other heavy metals and the risk of CVD.

Table 2

Multivariable correlations of selected heavy metals with cardiovascular disease (CVD) risk.

\begin{tabular}{|c|c|c|c|c|c|}
\hline & Q1 & Q2 & Q3 & Q4 & P for trenc \\
\hline \multicolumn{6}{|l|}{ Lead } \\
\hline Model 1 & Ref & $1.79(1.54,2.08)$ & $2.91(2.51,3.36)$ & $4.00(3.46,4.63)$ & $<0.001$ \\
\hline Model 2 & Ref & $0.93(0.79,1.08)$ & $1.10(0.94,1.29)$ & $1.09(0.94,1.27)$ & 0.025 \\
\hline Model 3 & Ref & $0.91(0.76,1.08)$ & $1.05(0.88,1.25)$ & $0.98(0.82,1.18)$ & 0.432 \\
\hline \multicolumn{6}{|c|}{ Cadmium } \\
\hline Model 1 & Ref & $1.66(1.47,1.86)$ & $2.53(2.24,2.86)$ & $2.73(2.38,3.12)$ & $<0.001$ \\
\hline Model 2 & Ref & $0.99(0.88,1.13)$ & $1.18(1.03,1.36)$ & $1.58(1.37,1.82)$ & $<0.001$ \\
\hline Model 3 & Ref & $0.97(0.83,1.12)$ & $1.21(1.04,1.42)$ & $1.45(1.22,1.72)$ & $<0.001$ \\
\hline \multicolumn{6}{|l|}{ Mercury } \\
\hline Model 1 & Ref & $0.92(0.81,1.05)$ & $0.80(0.70,0.90)$ & $0.76(0.65,0.89)$ & 0.003 \\
\hline Model 2 & Ref & $0.88(0.76,1.02)$ & $0.73(0.63,0.83)$ & $0.70(0.59,0.82)$ & 0.002 \\
\hline Model 3 & Ref & $0.94(0.81,1.08)$ & $0.81(0.70,0.93)$ & $0.82(0.69,0.96)$ & 0.059 \\
\hline \multicolumn{6}{|c|}{ model 1: crude model; } \\
\hline \multicolumn{6}{|c|}{ model 2: adjust for age, sex, race, education; } \\
\hline
\end{tabular}

We further analysed the correlations between the risk of the five common subtypes of CVD (congestive heart failure, coronary heart disease, angina, heart attack and stroke) and the quartiles of the serum concentrations of the three heavy metals (Table 3). After adjusting for all covariates, the serum levels of $\mathrm{Cd}$ were positively related to the risk of congestive heart disease $(\mathrm{OR}=1.53,95 \% \mathrm{Cl}: 1,17,2.00, \mathrm{p}$ for trend $<0.001), \mathrm{CHD}(\mathrm{OR}=1.24,95 \% \mathrm{Cl}: 0.98,1.55, \mathrm{p}$ for trend $=0.005), \mathrm{HA}(\mathrm{OR}=1.61,95 \% \mathrm{Cl}: 1.28,2.02, \mathrm{p}$ for trend $<0.001)$ and stroke $(\mathrm{OR}=1.68,95 \% \mathrm{Cl}: 1.26,2.23$, p for trend $<0.001)$. 
Table 3

Multivariable correlations of selected heavy metals with individual cardiovascular disease (CVD) risk.

$\begin{array}{llll}\begin{array}{l}\text { Congestive heart } \\ \text { failure }\end{array} & \begin{array}{l}\text { Coronary heart } \\ \text { disease }\end{array} & \text { Angina } & \text { Heart attack Stroke }\end{array}$

Lead

\begin{tabular}{|c|c|c|c|c|c|}
\hline Q1 & Ref & Ref & Ref & Ref & Ref \\
\hline Q2 & $1.09(0.84,1.41)$ & $0.98(0.77,1.25)$ & $\begin{array}{l}0.86(0.65 \\
1.14)\end{array}$ & $\begin{array}{l}1.22(0.95 \\
1.58)\end{array}$ & $\begin{array}{l}0.98(0.78, \\
1.23)\end{array}$ \\
\hline Q3 & $0.97(0.72,1.30)$ & $0.99(0.78,1.27)$ & $\begin{array}{l}0.87(0.66 \\
1.15)\end{array}$ & $\begin{array}{l}1.22(0.94 \\
1.57)\end{array}$ & $\begin{array}{l}1.16(0.90, \\
1.49)\end{array}$ \\
\hline Q4 & $1.06(0.81,1.38)$ & $0.99(0.76,1.29)$ & $\begin{array}{l}0.85(0.62 \\
1.17)\end{array}$ & $\begin{array}{l}1.26(0.99 \\
1.60)\end{array}$ & $\begin{array}{l}1.17(0.89, \\
1.54)\end{array}$ \\
\hline$P$ fo & 0.781 & 0.565 & 0.005 & 0.152 & 0.086 \\
\hline
\end{tabular}

trend

Cadmium

Q1 Ref $\quad$ Ref $\quad$ Ref $\quad$ Ref $\quad$ Ref

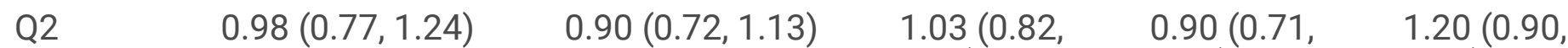

1.30) 1.15) 1.58)

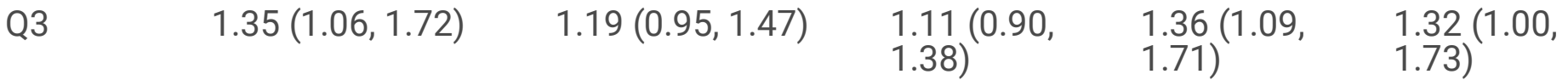

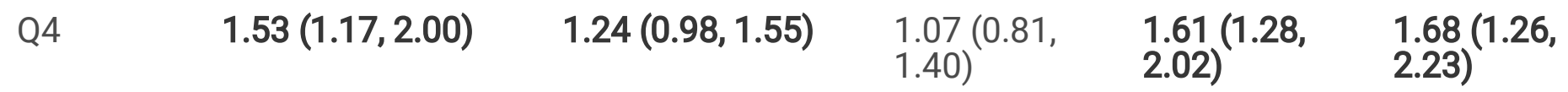

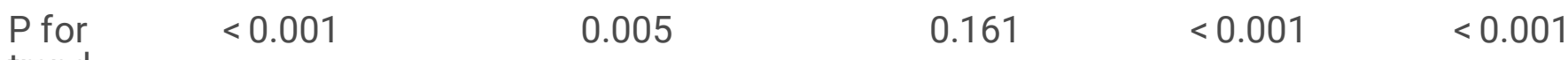

trend

Mercury

\begin{tabular}{|c|c|c|c|c|c|}
\hline Q1 & Ref & Ref & Ref & Ref & Ref \\
\hline Q2 & $0.89(0.72,1.09)$ & $0.95(0.75,1.18)$ & $\begin{array}{l}0.99(0.78 \\
1.26)\end{array}$ & $\begin{array}{l}0.99(0.81, \\
1.21)\end{array}$ & $\begin{array}{l}0.86(0.70, \\
1.06)\end{array}$ \\
\hline Q3 & $0.66(0.50,0.86)$ & $0.95(0.74,1.23)$ & $\begin{array}{l}0.92(0.71 \\
1.19)\end{array}$ & $\begin{array}{l}0.83(0.66, \\
1.04)\end{array}$ & $\begin{array}{l}0.81(0.67, \\
0.99)\end{array}$ \\
\hline Q4 & $0.55(0.44,0.68)$ & $1.18(0.90,1.54)$ & $\begin{array}{l}0.92(0.70 \\
1.20)\end{array}$ & $\begin{array}{l}1.03(0.83, \\
1.27)\end{array}$ & $\begin{array}{l}0.61(0.47 \\
0.80)\end{array}$ \\
\hline
\end{tabular}

$\begin{array}{llllll}P \text { for } & 0.041 & 0.019 & 0.419 & 0.634 & 0.003\end{array}$

trend

Adjust for age, gender, race, education, BMI, PIR, physical activity, past-year alcohol drinking, serum cotinine, family history of CVD, fish consumption and cycle. 
Table 4 shows the relationships between levels of $\mathrm{Cd}$ and concentrations of blood lipids and inflammation parameters. After adjusting for all covariates, cadmium levels were positively related to the levels of serum triglycerides (Beta $=7.85,95 \% \mathrm{Cl}: 2.78,12.93, \mathrm{p}=0.003)$, total cholesterol (Beta $=0.03$, $95 \% \mathrm{Cl}: 0.01,0.06, p=0.021$ ), and C-reactive protein (CRP, Beta $=0.03,95 \% \mathrm{Cl}: 0.01,0.05, p=0.009$ ) and the WBC count (Beta $=0.26,95 \% \mathrm{Cl}: 0,20,0.32, \mathrm{p}<0.001$ ).

Table 4

Multivariate analysis of the association of the serum cadmium levels and concentration changes (95\%

$\mathrm{Cl}$ ) in the blood lipids and inflammation parameters.

\begin{tabular}{|llll|}
\hline & Beta & 95\% Cl & P value \\
\hline Serum triglyceride $(\mathrm{mg} / \mathrm{dL})$ & $\mathbf{7 . 8 5}$ & $\mathbf{2 . 7 8 , 1 2 . 9 3}$ & $\mathbf{0 . 0 0 3}$ \\
\hline HDL-cholesterol $(\mathrm{mg} / \mathrm{dL})$ & 0.18 & $-0.32,0.67$ & 0.471 \\
\hline LDL-cholesterol $(\mathrm{mg} / \mathrm{dL})$ & 0.54 & $-0.83,1.91$ & 0.438 \\
\hline Total cholesterol $(\mathrm{mg} / \mathrm{dL})$ & $\mathbf{0 . 0 3}$ & $\mathbf{0 . 0 1 , 0 . 0 6}$ & $\mathbf{0 . 0 2 1}$ \\
\hline WBC $\left(10^{9} / \mathrm{mL}\right)$ & $\mathbf{0 . 2 6}$ & $\mathbf{0 . 2 0 , 0 . 3 2}$ & $<\mathbf{0 . 0 0 1}$ \\
\hline CRP $(\mathrm{mg} / \mathrm{dL})$ & $\mathbf{0 . 0 3}$ & $\mathbf{0 . 0 1}, \mathbf{0 . 0 5}$ & $\mathbf{0 . 0 0 9}$ \\
\hline $\begin{array}{l}\text { Adjust for age, sex, race, education, BMI, PIR, physical activity, past-year alcohol drinking, serum } \\
\text { cotinine, family history of CVD, fish consumption, lead, mercury and cycle. }\end{array}$ & \\
\hline $\begin{array}{l}\text { Cl, confidence interval; HDL, high density lipid; LDL, low density lipid; WBC, white blood cell; CRP, C- } \\
\text { reactive protein. }\end{array}$ & \\
\hline
\end{tabular}

\section{Discussion}

Our large population-based study is the first to show a dose-response relationship between cadmium (Cd) and cardiovascular disease (CVD) in adults. Furthermore, the serum levels of Cd were positively related to the overall risk of CVD and the risks of four of the subtypes. The underlying mechanism may involve the increases in blood lipid levels and activation of the inflammatory response induced by $\mathrm{Cd}$.

Few previous studies have focused on the relationship between the levels of Cd and CVD in adults. Although a study involving 15,624 United States (US) adults showed that urinary levels of Cd might be associated with all-cause mortality, more than $30 \%$ of which was attributed to CVD, no significant association was observed between Cd levels and CVD mortality.(Kim et al. 2019) Given that the levels of urinary $\mathrm{Cd}$ are sensitive to kidney function and physical activity, they cannot be used to accurately reflect exposure levels.(Li et al. 2020b, Munoz et al. 2020) The association of blood levels of Cd with CVD was studied in another population, and it was shown that elevated levels of $\mathrm{Cd}$ were associated with an elevated risk of CVD in adults under 60 years old.(Jeong et al. 2020) Nevertheless, given that the investigated population consisted of a single ethnicity, had fewer subtypes of CVD and was not adjusted for the confounding effects of smoking,(Li et al. 2019) this finding lacks generalizability. Therefore, our 
study provided valid evidence of the relationship between Cd levels and CVD risk after overcoming the abovementioned limitations. Further analysis is needed to investigate the underlying mechanisms by which Cd affects CVD; these mechanisms may involve the relationships between $\mathrm{Cd}$ and the levels of triglycerides, total cholesterol, and CRP and the WBC count.

Our results showed that the levels of $\mathrm{Cd}$ were positively correlated with the blood levels of triglycerides and total cholesterol, which indicated that elevated levels of triglyceride and total cholesterol may play important mediating roles in Cd-related CVD. Consistent with our findings, there is a substantial amount of evidence that exposure to $\mathrm{Cd}$ can result in dyslipidaemia, which has been identified as a risk factor for CVD.(Samarghandian et al. 2015, Zhu et al. 2020) Indications of the possible underlying mechanisms can be found in the results of this study and previous studies. An animal study showed that Cd could increase triglyceride levels by reducing lipid uptake receptors in the liver.(Liu et al. 2020a) In addition, exposure to $\mathrm{Cd}$ also initiated the endoplasmic reticulum (ER) stress process, which negatively affected lipid homeostasis and metabolic gene expression.(Rajakumar et al. 2020) Furthermore, high levels of Cd could also increase the production of lipids by markedly elevating the activity of serum lipase, reduce lipid degradation by reducing fatty acid $\beta$ oxidation and promote lipid synthesis by modifying many liver enzymes, such as hydroxyl-methyl-glutaryl CoA reductase (HMG-CoA).(Aja et al. 2020, Ali et al. 2020, Pawlak et al. 2015, Wu et al. 2017)

Our study also suggested that WBC counts and CRP levels were positively associated with Cd levels, which provides insight into another possible mechanism underlying Cd-related CVD. Although many studies have reported high levels of WBCs in patients with CVD, the reason is unclear.(Koren-Morag et al. 2005, Lassale et al. 2018, Xu et al. 2020a) Interestingly, some studies showed that changes in WBC counts and CRP levels indicated systemic inflammation.(Baek \&Chung 2017, Fagerberg et al. 2017, Saggu et al. 2019) It is worth noting that reactive oxygen species (ROS), autophagy, and immune-related and apoptosis-related genes were found to be involved in this process, which possibly increased the risk of CVD by inducing cytotoxicity, vascular toxicity, nephrotoxicity and cardiotoxicity. (Kwok \&Chan 2020, Kwok et al. 2020, Liu et al. 2020b, Reyes-Becerril et al. 2019, Roy et al. 2020, Wang et al. 2020)

Our study had some limitations. First, due to its long biological half-life and low excretion rate, it was difficult to determine whether the timing of exposure to Cd influenced the CVD risk in our study.(Bhardwaj et al. 2020, Kabamba \&Tuakuila 2020) In addition, genetic factors also contribute to the risk of CVD; however, there were no genetic data collected in the NHANES. Although the results also showed that levels of mercury were positively related to the risks of congestive HF and stroke, our study mainly addressed the relationship between Cd levels and the risk of CVD. Finally, as this was a cross-sectional study, it can only provide epidemiological evidence of a correlation between Cd levels and the risk of CVD, and further functional experiments and prospective cohort studies are needed to verify this correlation.

\section{Conclusion}


In our study, high serum levels of Cd are associated with increased risks of overall CVD and four of the CVD subtypes and that the concentrations of $\mathrm{Cd}$ are also positively related to the levels of lipids and inflammation parameters, which might provide insight into the possible mechanism underlying Cd-related CVD.

\section{Declarations}

\section{Availability of data and material}

Data will be available on request.

\section{Authors' contributions}

Xuming Mo: Conceptualization, Validation, Supervision and Funding acquisition. Siyu Ma: Methodology, Writing - Original Draft and Visualization. Cheng Xu: Methodology, Formal analysis and Visualization. Jie Zhang: Supervision and Project administration. Min Da, Yang Xu and Yong Chen: Resources.

\section{Acknowledgements}

Not applicable

\section{Funding}

This work was supported by Key Project supported by the Medical Science and Technology Development Foundation, Nanjing Municipality Health Bureau (ZKX19039), the National Key Research and Development Program of China (2017YFC1308105), Clinical Frontier Technology of Clinical Medicine of Jiangsu Provincial Science and Technology Department (BE2017608), the National Natural Science Foundation of China (81970265,82000303), the Natural Science Foundation of Jiangsu Province (BK20180144), Nanjing Science and Technology Development Project (2019060007) and Key Medical Discipline of Science \& Education Project of Jiangsu Province (ZDXKB2016017).

\section{Conflicts of interests}

The authors declare that they have no competing interests.

\section{Ethical approval}

This article does not contain any studies with human participants or animals performed by any of the authors. 


\section{Consent to participate}

Not applicable

\section{Consent for publication}

Not applicable

\section{References}

1. Aja PM, Izekwe FI, Famurewa AC, Ekpono EU, Nwite FE, Igwenyi IO, Awoke JN, Ani OG, Aloke C, Obasi NA, Udeh KU, Ale BA (2020): Hesperidin protects against cadmium-induced pancreatitis by modulating insulin secretion, redox imbalance and iNOS/NF-kB signaling in rats. Life Sci 259, 118268

2. Al Amin M, Rahman ME, Hossain S, Rahman M, Rahman MM, Jakariya M, Sikder MT (2020): Trace Metals in Vegetables and Associated Health Risks in Industrial Areas of Savar, Bangladesh. J Health Pollut 10, 200905

3. Ali S, Awan Z, Mumtaz S, Shakir HA, Ahmad F, Ulhaq M, Tahir HM, Awan MS, Sharif S, Irfan M, Khan MA (2020): Cardiac toxicity of heavy metals (cadmium and mercury) and pharmacological intervention by vitamin C in rabbits. Environ Sci Pollut Res Int 27, 29266-29279

4. Amadou A, Coudon T, Praud D, Salizzoni P, Leffondre K, Leveque E, Boutron-Ruault MC, Danjou AMN, Morelli X, Le Cornet C, Perrier L, Couvidat F, Bessagnet B, Caudeville J, Faure E, Mancini FR, Gulliver J, Severi G, Fervers B (2020): Chronic Low-Dose Exposure to Xenoestrogen Ambient Air Pollutants and Breast Cancer Risk: XENAIR Protocol for a Case-Control Study Nested Within the French E3N Cohort. JMIR Res Protoc 9, e15167

5. Aw M, Ochieng BO, Attambo D, Opot D, Aw J, Francis S, Hawkes MT (2020): Critical appraisal of a mHealth-assisted community-based cardiovascular disease risk screening program in rural Kenya: an operational research study. Pathog Glob Health, 1-9

6. Baek K, Chung I (2017): Cadmium Exposure Is Associated with Monocyte Count and Monocyte to HDL Ratio, a Marker of Inflammation and Future Cardiovascular Disease in the Male Population. $J$ Korean Med Sci 32, 1415-1422

7. Bhardwaj JK, Panchal H, Saraf P (2020): Cadmium as a testicular toxicant: A Review. J Appl Toxicol

8. Bi J, D'Souza RR, Rich DQ, Hopke PK, Russell AG, Liu Y, Chang HH, Ebelt S (2020): Temporal changes in short-term associations between cardiorespiratory emergency department visits and PM2.5 in Los Angeles, 2005 to 2016. Environ Res 190, 109967

9. Cao X, Bi R, Hao J, Wang S, Huo Y, Demoz RM, Banda R, Tian S, Xin C, Fu M, Pi J, Liu J (2020): A study on the protective effects of taxifolin on human umbilical vein endothelial cells and THP-1 cells damaged by hexavalent chromium: a probable mechanism for preventing cardiovascular disease induced by heavy metals. Food Funct 11, 3851-3859 
10. Dennis KK, Liu KH, Uppal K, Go YM, Jones DP (2020): Distribution of phytochelatins, metal-binding compounds, in plant foods: A survey of commonly consumed fruits, vegetables, grains and legumes. Food Chem 339, 128051

11. Fagerberg B, Borne Y, Barregard L, Sallsten G, Forsgard N, Hedblad B, Persson M, Engstrom G (2017): Cadmium exposure is associated with soluble urokinase plasminogen activator receptor, a circulating marker of inflammation and future cardiovascular disease. Environ Res 152, 185-191

12. Gemeda FT, Guta DD, Wakjira FS, Gebresenbet G (2020): Occurrence of heavy metal in water, soil, and plants in fields irrigated with industrial wastewater in Sabata town, Ethiopia. Environ Sci Pollut Res Int

13. Igharo OG, Akinfenwa Y, Isara AR, Idomeh FA, Nwobi NL, Anetor Jl, Osibanjo O (2020): Lipid profile and Atherogenic Indices in Nigerians Occupationally Exposed to e-waste: A Cardiovascular Risk Assessment Study. Maedica (Bucur) 15, 196-205

14. ljomone OM, Olung NF, Akingbade GT, Okoh COA, Aschner M (2020): Environmental influence on neurodevelopmental disorders: Potential association of heavy metal exposure and autism. J Trace Elem Med Biol 62, 126638

15. Jeong J, Yun SM, Kim M, Koh YH (2020): Association of Blood Cadmium with Cardiovascular Disease in Korea: From the Korea National Health and Nutrition Examination Survey 2008-2013 and 2016. Int J Environ Res Public Health 17

16. Kabamba M, Tuakuila J (2020): Toxic metal (Cd, Hg, Mn, Pb) partition in the maternal/foetal unit: A systematic mini - review of recent epidemiological studies. Toxicol Lett 332, 20-26

17. Kim K, Melough MM, Sakaki JR, Ha K, Marmash D, Noh H, Chun OK (2019): Association between Urinary Cadmium to Zinc Intake Ratio with Adult Mortality in a Follow-Up Study of NHANES 19881994 and 1999-2004. Nutrients 12

18. Klein EF, Adir Y, Fireman E, Kessel A (2020): Cigarette-related cadmium and environmental pollution exposure are reflected in airway ultrafine particle content. ERJ Open Res 6

19. Koker L, Aydin F, Gaygusuz O, Akcaalan R, Camur D, Ilter H, Ayoglu FN, Altin A, Topbas M, Albay M (2020): Heavy Metal Concentrations in Trachurus Mediterraneus and Merlangius Merlangus Captured from Marmara Sea, Turkey and Associated Health Risks. Environ Manage

20. Koller R, Agyemang C (2020): Prevalence of Cardiovascular Disease Risk Factors in the Gambia: A Systematic Review. Glob Heart 15, 42

21. Koren-Morag N, Tanne D, Goldbourt U (2005): White blood cell count and the incidence of ischemic stroke in coronary heart disease patients. Am J Med 118, 1004-9

22. Kwok ML, Chan KM (2020): Oxidative stress and apoptotic effects of copper and cadmium in the zebrafish liver cell line ZFL. Toxicol Rep 7, 822-835

23. Kwok ML, Meng Q, Hu XL, Chung CT, Chan KM (2020): Whole-transcriptome sequencing (RNA-seq) study of the ZFL zebrafish liver cell line after acute exposure to $\mathrm{Cd}(2+)$ ions. Aquat Toxicol 228, 105628 
24. Lassale C, Curtis A, Abete I, van der Schouw YT, Verschuren WMM, Lu Y, Bueno-de-Mesquita HBA (2018): Elements of the complete blood count associated with cardiovascular disease incidence: Findings from the EPIC-NL cohort study. Sci Rep 8, 3290

25. Li H, Fagerberg B, Sallsten G, Borne Y, Hedblad B, Engstrom G, Barregard L, Andersson EM (2019): Smoking-induced risk of future cardiovascular disease is partly mediated by cadmium in tobacco: Malmo Diet and Cancer Cohort Study. Environ Health 18, 56

26. Li J, Wang X, Zhao G, Chen C, Chai Z, Alsaedi A, Hayat T, Wang X (2018): Metal-organic frameworkbased materials: superior adsorbents for the capture of toxic and radioactive metal ions. Chem Soc Rev 47, 2322-2356

27. Li S, Wu J, Huo Y, Zhao X, Xue L (2020a): Profiling multiple heavy metal contamination and bacterial communities surrounding an iron tailing pond in Northwest China. Sci Total Environ 752, 141827

28. Li Y, Wang H, Yu J, Yan Q, Hu H, Zhang L, Tian T, Peng X, Yang S, Ke S (2020b): An assessment of sensitivity biomarkers for urinary cadmium burden. BMC Nephrol 21, 385

29. Li Z, Liu Q, Xu Z, Guo X, Wu S (2020c): Association between short-term exposure to ambient particulate air pollution and biomarkers of oxidative stress: A meta-analysis. Environ Res 191, 110105

30. Liu H, Wang Y, Ren Z, Ji X, Peprah FA, Zhang X, Dai S, Zhou Y, Gu J, Shi H (2020a): Dietary cadmium exposure causes elevation of blood ApoE with triglyceride level in mice. Biometals 33, 241-254

31. Liu P, Wang S, Chang Z, Li L, Xing H, Dong WF (2020b): Combined toxicity of silica nanoparticles and cadmium chloride on the cardiovascular system of zebrafish (Danio rerio) larvae. Comp Biochem Physiol C Toxicol Pharmacol 239, 108895

32. Lloyd-Jones D et al. (2010): Executive summary: heart disease and stroke statistics-2010 update: a report from the American Heart Association. Circulation 121, 948-54

33. Munoz D, Grijota FJ, Bartolome I, Siquier-Coll J, Toro-Roman V, Maynar M (2020): Serum and urinary concentrations of arsenic, beryllium, cadmium and lead after an aerobic training period of six months in aerobic athletes and sedentary people. J Int Soc Sports Nutr 17, 43

34. Orisakwe OE, Mbagwu HO, Ajaezi GC, Edet UW, Uwana PU (2015): Heavy Metals in Seafood and Farm Produce from Uyo, Nigeria: Levels and health implications. Sultan Qaboos Univ Med J 15, e275-82

35. Orisakwe OE, Udowelle NA, Azuonwu O, Nkeiruka IZ, Nkereuwem UA, Frazzoli C (2020): Cadmium and lead in geophagic clay consumed in Southern Nigeria: health risk from such traditional nutraceutical. Environ Geochem Health

36. Pan LB, Ma J, Wang XL, Hou H (2016): Heavy metals in soils from a typical county in Shanxi Province, China: Levels, sources and spatial distribution. Chemosphere 148, 248-54

37. Pawlak M, Lefebvre P, Staels B (2015): Molecular mechanism of PPARalpha action and its impact on lipid metabolism, inflammation and fibrosis in non-alcoholic fatty liver disease. J Hepatol 62, 720-33

38. Phillips SA, Guazzi M (2015): The vasculature in cardiovascular diseases: will the vasculature tell us what the future holds? Prog Cardiovasc Dis 57, 407-8 
39. Rajakumar S, Vijayakumar R, Abhishek A, Selvam GS, Nachiappan V (2020): Loss of ERAD bridging factor UBX2 modulates lipid metabolism and leads to ER stress-associated apoptosis during cadmium toxicity in Saccharomyces cerevisiae. Curr Genet 66, 1003-1017

40. Reyes-Becerril M, Angulo C, Sanchez V, Cuesta A, Cruz A (2019): Methylmercury, cadmium and arsenic(III)-induced toxicity, oxidative stress and apoptosis in Pacific red snapper leukocytes. Aquat Toxicol 213, 105223

41. Roy A, Nethi SK, Suganya N, Raval M, Chatterjee S, Patra CR (2020): Attenuation of cadmiuminduced vascular toxicity by pro-angiogenic nanorods. Mater Sci Eng C Mater Biol Appl 115, 111108

42. Saggu S, Rehman H, Aziz AT, Alzeibr FMA, Oyouni AAA, Zidan N, Panneerselvam C, Trivedi S (2019): Cymbopogon schoenanthus (Ethkher) ameliorates cadmium induced toxicity in swiss albino mice. Saudi J Biol Sci 26, 1875-1881

43. Sall ML, Diaw AKD, Gningue-Sall D, Efremova Aaron S, Aaron JJ (2020): Toxic heavy metals: impact on the environment and human health, and treatment with conducting organic polymers, a review. Environ Sci Pollut Res Int 27, 29927-29942

44. Samarghandian S, Azimi-Nezhad M, Shabestari MM, Azad FJ, Farkhondeh T, Bafandeh F (2015): Effect of chronic exposure to cadmium on serum lipid, lipoprotein and oxidative stress indices in male rats. Interdiscip Toxicol 8, 151-4

45. So $\mathrm{R}$ et al. (2020): Long-term exposure to low levels of air pollution and mortality adjusting for road traffic noise: A Danish Nurse Cohort study. Environ Int 143, 105983

46. Sotomayor CG, Grooth of D, Vodegel JJ, Eisenga MF, Knobbe TJ, J IJ, Lammerts RGM, de Borst MH, Berger SP, Nolte IM, Rodrigo R, Slart R, Navis GJ, Touw DJ, Bakker SJL (2020): Plasma cadmium is associated with increased risk of long-term kidney graft failure. Kidney Int

47. Suwazono Y, Nogawa K, Sakurai M, Watanabe Y, Nishijo M, Ishizaki M, Morikawa Y, Kido T, Nakagawa $\mathrm{H}$ (2020): Environmental cadmium exposure and noncancer mortality in a general Japanese population in cadmium nonpolluted regions. J Appl Toxicol

48. Thiara B (2015): Cardiovascular disease. Nurs Stand 29, 60

49. Wang C, Liu X, Chen JP, Li K (2015): Superior removal of arsenic from water with zirconium metalorganic framework UiO-66. Sci Rep 5, 16613

50. Wang C, Nie G, Zhuang Y, Hu R, Wu H, Xing C, Li G, Hu G, Yang F, Zhang C (2020): Inhibition of autophagy enhances cadmium-induced apoptosis in duck renal tubular epithelial cells. Ecotoxicol Environ Saf 205, 111188

51. Wang J, Zhang X, Yang Q, Zhang K, Zheng Y, Zhou G (2018): Pollution characteristics of atmospheric dustfall and heavy metals in a typical inland heavy industry city in China. J Environ Sci (China) 71, 283-291

52. Wu C, Zhang Y, Chai L, Wang H (2017): Histological changes, lipid metabolism and oxidative stress in the liver of Bufo gargarizans exposed to cadmium concentrations. Chemosphere 179, 337-346

53. Wu Y, Pang H, Liu Y, Wang X, Yu S, Fu D, Chen J, Wang X (2019): Environmental remediation of heavy metal ions by novel-nanomaterials: A review. Environ Pollut 246, 608-620 
54. Xu C, Liang J, Xu S, Liu Q, Xu J, Gu A (2020a): Increased serum levels of aldehydes are associated with cardiovascular disease and cardiovascular risk factors in adults. J Hazard Mater 400, 123134

55. Xu C, Weng Z, Zhang L, Xu J, Dahal M, Basnet TB, Gu A (2020b): HDL cholesterol: A potential mediator of the association between urinary cadmium concentration and cardiovascular disease risk. Ecotoxicol Environ Saf 208, 111433

56. Zhang YB, Pan XF, Chen J, Cao A, Xia L, Zhang Y, Wang J, Li H, Liu G, Pan A (2020): Combined lifestyle factors, all-cause mortality and cardiovascular disease: a systematic review and metaanalysis of prospective cohort studies. J Epidemiol Community Health

57. Zhao M, Xu Y, Zhang C, Rong H, Zeng G (2016): New trends in removing heavy metals from wastewater. Appl Microbiol Biotechnol 100, 6509-6518

58. Zhu X, Fan Y, Sheng J, Gu L, Tao Q, Huang R, Liu K, Yang L, Chen G, Cao H, Li K, Tao F, Wang S (2020): Association Between Blood Heavy Metal Concentrations and Dyslipidemia in the Elderly. Biol Trace Elem Res

\section{Figures}

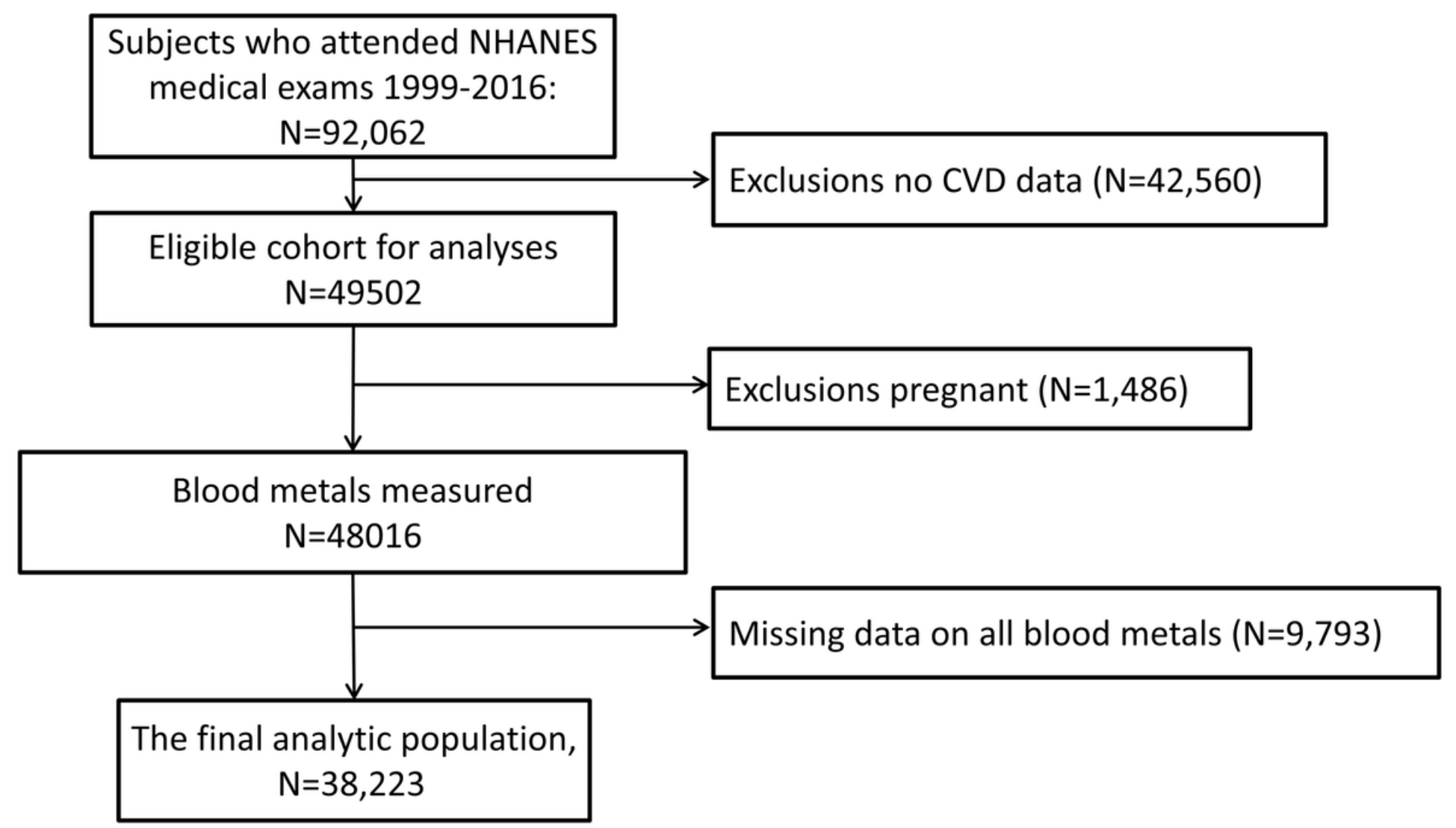

Figure 1

Participant selection process for the analyses of the relationships between serum cadmium levels and the risk of cardiovascular disease (CVD) in adults. 


\section{Supplementary Files}

This is a list of supplementary files associated with this preprint. Click to download.

- graphicalabstract.tif 